\title{
Correction to: Targeted plant improvement through genome editing: from laboratory to field
}

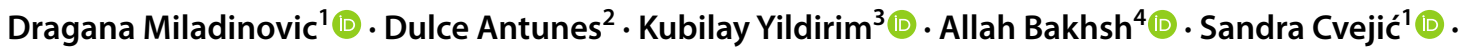

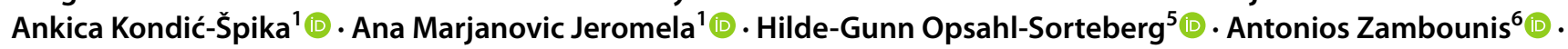 \\ Zoe Hilioti $^{7}$ (D)
}

Published online: 7 March 2022

(c) Springer-Verlag GmbH Germany, part of Springer Nature 2022

\section{Correction to: Plant Cell Reports (2021) 40:935-951 https://doi.org/10.1007/s00299-020-02655-4}

This article/publication is based upon work from COST Action PlantEd (CA18111), supported by COST (European Cooperation in Science and Technology). www. cost.eu. DM, SC, AKŠ, and AMJ were also supported by Ministry of Education, Science and Technological Development of the Republic of Serbia, grant number 451-0368/2020-14/200032. KY was supported by Turkish Scientific and Technological Research Council, project number TOVAG-217O232.
Publisher's Note Springer Nature remains neutral with regard to jurisdictional claims in published maps and institutional affiliations.

The original article can be found online at https://doi.org/10.1007/ s00299-020-02655-4.

\footnotetext{
Zoe Hilioti

zhilioti@certh.gr

Institute of Field and Vegetable Crops, Novi Sad, Serbia

2 MED, FCT, Universidade do Algarve, Faro, Portugal

3 Department of Molecular Biology and Genetics, Faculty of Sciences, Ondokuzmayıs University, Samsun, Turkey

4 Department of Agricultural Genetic Engineering, Faculty of Agricultural Sciences and Technologies, Nigde Omer Halisdemir University, Nigde, Turkey

5 Faculty of Biosciences, Norwegian University of Life Sciences, Ås, Norway

6 Department of Deciduous Fruit Trees, Institute of Plant Breeding and Genetic Resources, ELGO-DEMETER, Naoussa, Greece

7 Institute of Applied Biosciences, CERTH, Thessaloniki, Greece
} 